\title{
Literatura infantil promovendo conhecimento docente e desenvolvimento de noções matemáticas
}

\author{
Alessandra Rodrigues de Almeida* \\ Maria Auxiliadora Bueno Andrade Megid**
}

\section{Resumo}

Apresentamos uma pesquisa-formação realizada com quatro turmas do curso de Pedagogia de uma universidade a partir do trabalho integrado das duas professoras (autoras deste artigo) que ministraram a disciplina "Educação Espaço e Forma" a turmas do $4^{\circ}$ semestre do curso de graduação e que atuaram como docentes e pesquisadoras neste processo. Participaram da disciplina 110 estudantes, organizados em cinco turmas. Tem como objetivo discutir o processo de formação matemática do futuro professor, considerando a elaboração de propostas didáticas interdisciplinares durante a formação inicial. Os resultados mostram o potencial das histórias para o ensino da matemática na Educação Infantil, bem como o avanço do processo formativo ancorado em narrativas com os professores envolvidos. Palavras chave: educação matemática; formação inicial de professores, educação infantil, literatura infantil,

\section{Children's literature promoting knowledge for teachers and developing mathematics awareness}

\section{Abstract}

This is an educational research done with $4^{\text {th }}$ semester students of a Pedagogy university course based on the integrated work of the two

\footnotetext{
* Docente da Faculade de Educação da PUC-Campinas. Doutora em Ensino de Ciências e Matemática (PECIM - UNICAMP).

** Docente e Pesquisadora do Programa de Pós-Graduação em Educação PUCCampinas. Doutora em Educação com foco em Educação Matemática (FE -UNICAMP)
} 
professors (who are also the researchers and authors of this article) of the subject "Education - Space and Form". One hundred ten students divided into five groups - have participated on the subject. The objective is to discuss the education process of the teachers-to-be, considering the development of interdisciplinary didactic proposals during their initial education. The results show the potential storytelling has as a tool to teach Mathematics in Children's Education, as well as the advance in the formative process when supported by narratives presented by the teachers.

Keywords: Mathematics education; Teacher's initial education; Children's education; Children's literature.

\section{Literatura infantil promoviendo el conocimiento docente y el desarrollo de nociones matemáticas}

\section{Resumen}

Presentamos una investigación-formación realizada con cuatro grupos del curso de Pedagogía de una universidad a partir del trabajo integrado de las dos profesoras (autoras de este artículo) que ministran la disciplina "Educación Espacio y Forma" a clases del $4^{\circ}$ semestre del curso de graduación y que actuaron como docentes e investigadoras en este proceso. Participaron en esta disciplina 110 estudiantes organizados en cinco clases. Esta tiene como objetivo discutir el proceso de formación matemática del futuro profesor, considerando la elaboración de propuestas didácticas interdisciplinarias durante su formación inicial. Los resultados muestran el potencial de las historias a la enseñanza de matemática en la Educación Infantil, así como el avance en el proceso formativo apoyado por narrativas con los profesores involucrados.

Palabras clave: Educación matemática; Formación inicial de profesores, Educación infantil; Literatura infantil.

\section{Introdução}

O texto apresenta reflexões a respeito da articulação entre a Educação matemática e a literatura durante a formação de futuros professores a partir de uma ação formativa que envolveu três etapas: a criação de uma história infantil inédita que permitisse discutir algumas noções matemáticas; a elaboração artesanal de um livro infantil, que representasse a o texto e favorecesse o processo 
de contar as histórias, e a proposição de uma sequência de tarefas com características interdisciplinares para a Educação Infantil a partir do livro produzido .

A pesquisa-formação realizada com quatro turmas do curso de Pedagogia de uma universidade privada do interior de São Paulo ocorreu a partir do trabalho integrado das duas professoras (docentes e pesquisadoras neste processo e autoras deste artigo) que ministraram a disciplina "Educação Espaço e Forma" à turmas do $4^{\circ}$ semestre do curso de graduação. Participaram da disciplina 110 estudantes, distribuídos em cinco turmas.

A perspectiva pesquisa-formação é compreendida como um processo de produção de conhecimentos sobre situações cotidianas do processo formativo no contexto apresentado. A investigação teve como objetivo discutir o processo de formação matemática do futuro professor, considerando a elaboração de propostas didáticas interdisciplinares durante a formação inicial. Ressaltamos que a disciplina que envolve o contexto da pesquisa tem como objetivo o estudo a respeito da aquisição dos conceitos de espaço, forma e número, tendo como foco perspectivar a docência na Educação Infantil.

As análises emergem das narrativas escritas que foram produzidas pelas futuras professoras após a conclusão das três etapas da ação formativa. Consideramos que as narrativas de futuras professoras se configuram como um meio de "dar sentido a uma experiência educativa ou a uma prática social” (FREITAS; FIORENTINI, 2007, p. 65), ou seja, elaborar narrativas pode se constituir como uma prática potente durante a formação inicial.

Considerando as narrativas no processo de investigação, Galvão (2005) enfatiza que a narrativa possibilita ao investigador aderir ao pensamento do sujeito (futuro professor), ao significado que ele atribui às suas experiências, à avaliação de processos e de maneiras de atuação. Para além disso, permite aderir aos contextos vividos e como se desenrolaram as ações, gerando informações situadas do que se está a investigar. Desse modo, as narrativas se 
constituem em poderosas ferramentas de formação e importantes instrumentos de pesquisa no contexto educacional. Concordamos com Cunha (1997), na perspectiva de que a pesquisas que utiliza narrativas é, ao mesmo tempo, investigação e formação, pois neste espaço evidencia-se uma relação dialética entre a teoria e a realidade.

O texto organiza-se a partir de uma discussão sobre a formação do professor que ensina matemática na infância, da articulação entre literatura infantil e matemática como perspectiva para o ensino e aprendizagem e, por fim, de algumas reflexões a partir das narrativas produzidas pelos futuros professores.

\section{A formação do professor que ensina matemática na infância}

A formação matemática nos cursos de licenciatura em Pedagogia se constitui em uma questão atual e de muita relevância no cenário acadêmico, pois possui uma relação com o ensino dessa disciplina na educação básica, uma vez que após a conclusão da graduação esses profissionais estarão atuando no ensino dos alunos de Educação Infantil e anos iniciais do Ensino Fundamental. Estudiosos da área da Educação Matemática vêm indicando aspectos preocupantes relacionados à formação matemática nos cursos de Pedagogia, tanto com relação à carga horária de estudos destinada à disciplina quanto ao modo como algumas disciplinas da área têm sido trabalhadas nesses cursos.

Grando e Torriceli (2012) ao investigarem as contribuições de práticas colaborativas adotadas como estratégias formativas, no sentido de promover a ressignificação da matemática e de seu ensino para alunas da Pedagogia, ressaltam que as discussões sobre a matemática necessárias à formação do pedagogo regularmente são centradas na resolução de exercícios, sem reflexões sobre seu ensino, sobre seus fundamentos e sua filosofia. Tais ações não propiciam a reflexão sobre as crenças e concepções do futuro professor a respeito dessa disciplina, permitindo assim que continuem estabelecidas a partir das concepções que seus antigos professores lhes passaram. 
Diversas pesquisas têm focado a formação inicial (PROENÇA, 2015; FERNANDES; CURI, 2012) e continuada (PASSOS; OLIVEIRA, GAMA, 2014; AZEVEDO, 2014) de professores, como aspectos importantes para promover mudanças no cenário educacional, visando conhecer quais as condições ambientais, os métodos, os conteúdos, os conceitos, as práticas, os procedimentos, ou como os conjuntos desses elementos podem favorecer uma aprendizagem real e significativa, e contribuir efetivamente para o desenvolvimento das competências matemáticas atualmente exigidas. Sinalizam também quais elementos dificultam esse processo e favorecem a reprodução do currículo já praticado em sala de aula e a manutenção da prática utilitarista da matemática, centrada em cálculos e procedimentos repetitivos sem reflexão.

Em contraposição à essa situação, estudiosos da área da matemática e da Educação Matemática têm proposto dinâmicas e práticas diferenciadas para o processo de formação inicial e continuada dos professores, com o intuito de desenvolver uma ação reflexiva coletiva e a autonomia docente, enfatizando o aspecto da linguagem oral e escrita, a produção de textos, estudos de textos históricos, a investigação da prática pedagógica por meio da participação dos professores em grupos colaborativos, a produção de narrativas autobiográficas, a análise e a produção de casos de ensino, a realização de atividades exploratórioinvestigativas, a exploração e produção de materiais didáticos, além de outras propostas (ALMEIDA; FERNANDES; MEGID, 2017; NACARATTOO, MENGALI e PASSOS, 2011).

Consideramos que os cursos de graduação não conseguem suprir todas as necessidades que o professor terá no desenvolvimento da docência. No entanto é essencial que durante a formação inicial o futuro professor tenha o contato com o maior arsenal de aprendizagens consistentes que venham a auxiliá-lo em sua prática futura, tanto no que se refere aos aspectos teóricos, quanto às reflexões e abordagens metodológicas e práticas, que lhe permitam estabelecer uma comunicação com seu aluno de modo a favorecer sua aprendizagem. 


\section{Conexões entre Matemática e Literatura na Educação Infantil}

Ao discutirmos o ensino e a aprendizagem da matemática na Educação Infantil é fundamental afirmar que a criança deva estar plenamente envolvida nesse processo educacional. Nesse sentido, compreendemos essa criança como sujeito-autor e não objeto da aprendizagem, como construtora de conhecimento e de identidade. Nessa perspectiva, a infância é entendida como “o tempo em que a criança deve ser introduzida na riqueza da cultura humana histórica e socialmente criada, reproduzindo para si qualidades especificamente humanas" (MELLO, 2007, p. 90).

Para Coêlho e Souza (2018), a compreensão da infância na contemporaneidade pressupõe pensar "em fundamentos teóricometodológicos vinculados à perspectiva de que o sujeito é capaz de se reinventar constantemente, em uma dinâmica relação com o contexto histórico, social, cultural e subjetivo" (COELHO; SOUZA, 2018, p. 25).

Podemos assim afirmar que a criança é sujeito-autor da aprendizagem. Considerando essa afirmação a educação intencionalmente planejada pode ampliar e enriquecer as possibilidades para a aprendizagem e o desenvolvimento das crianças. Desse modo é possível afirmar que a Educação Matemática pode ser inserida no cotidiano educacional das crianças da Educação Infantil. Cabe ressaltar que o trabalho pedagógico com a matemática nessa etapa educacional pressupõe oportunizar às crianças experiências com o universo matemático que lhes possibilitem descobrir, tecer relações, organizar o pensamento, interagir com o meio, com crianças e adultos, compartilhar interesses, necessidades e conhecimentos. Destaca-se ainda a valorização a brincadeira, das diferentes formas de expressão das crianças, as múltiplas linguagens, as relações que se estabelecem na criação de brincadeiras, nas formas de brincar e seus significados.

Para Novo et al. (2017), na Educação Infantil as crianças deveriam ter condições de interpretar o conhecimento como um 
todo e não como disciplinas ou áreas desconectadas umas das outras (NOVO et al, 2017). Foster et al 2018), ressaltam que o trabalho com conceitos e relações numéricas e o letramento matemático são fundamentais para as crianças já nessa etapa educacional, uma vez que fortalecem a compreensão e a resolução de problemas e contribuem para a aprendizagem de conceitos mais complexos no futuro. O desenvolvimento das noções espaciais, de grandezas e medidas também se configuram como temas importantes a serem trabalhados com as crianças da Educação Infantil (LORENZATO, 2006; CLEMENTS; STEPHAN, 2004).

$\mathrm{Na}$ educação infantil as histórias, os contos, as poesias são cotidianamente apresentados e explorados de diferentes maneiras, tanto quando são contados pelo professor como pelas as crianças. Para Carleto e Guimarães (2015, p. 8):

O hábito da escuta, do compartilhar histórias, seja por meio da leitura ou da contação, guarda em si inúmeros significados. Está relacionado à construção das identidades, ao cuidado afetivo, ao desenvolvimento da imaginação, da capacidade de escutar os outros e de expressar ideias e sentimentos, além de partilhar conhecimentos.

Os livros infantis no cotidiano de grande parte das escolas são utilizados ainda como instrumentos didáticos para favorecer a alfabetização, e estimular o gosto e hábito da leitura. A importância das histórias infantis é comentada por Dalcin (2002), ao enfatizar que:

Por intermédio de histórias infantis, as crianças tomam contato com diferentes situações e realidades. Os personagens, sejam eles humanos, animais, duendes, fadas, bruxas [...] vivenciam conflitos e tomam decisões. Habitam num universo situado em um contexto particular que é regido por regras e normas próprias. Nesse universo, os personagens estabelecem relações entre si e com o seu meio, relações essas que precisam ser conhecidas e compreendidas por quem ouve ou lê a história (DALCIN, 2002, p. 62).

Menezes (2011) justifica a importância da articulação entre a língua materna e a matemática com base em dois fundamentos. O primeiro assenta-se na compreensão de que a aprendizagem 
depende da capacidade de o aluno estabelecer conexões entre seu próprio conhecimento e as diferentes disciplinas que está a estudar e também entre elas. Desse modo, o ensino fragmentado, separando a língua materna da matemática, em nada contribui para essa conexão de saberes. $\mathrm{O}$ segundo ancora-se no entendimento de que as características específicas dos saberes linguístico e matemático quando articulados se potencializam mutuamente, ou seja, a matemática fornece à língua, especialmente à literatura, estruturação de pensamento, organização lógica e articulação do discurso. A língua possibilita à matemática capacidades comunicativas, como a leitura e interpretação de texto (escrito e oral) e capacidades de expressão (escrita e oral, em particular a discussão). Para o autor, esse trabalho integrado cria condições para que os alunos interajam e discutam o significado do que lêem e ainda faz emergir a necessidade da negociação de significados, o que também favorece o desenvolvimento do conhecimento matemático.

Diante da importância da literatura no cotidiano infantil, consideramos que é possível ampliar sua potencialidade além dos aspectos já mencionados, possibilitando relações com outras áreas do saber, como com a matemática, que é o foco deste artigo. É fundamental salientar que não se pretende que o livro infantil converta-se num recurso a ser exaustivamente problematizado com noções, ideias ou conteúdos matemáticos, descaracterizando o interesse e o prazer de ouvir as histórias.

Considerando o exposto, diferentes estudos têm apontado o potencial do trabalho integrado de histórias infantis e conteúdos matemáticos para o Ensino Fundamental. Souza e Oliveira (2010) procuraram identificar intervenções docentes potencializadoras da apropriação e da construção de novos conhecimentos por alunos da $4^{a}$ série do Ensino Fundamental, em um contexto de ensino que conectou matemática e literatura. Para as autoras os resultados mostraram o desenvolvimento de práticas pedagógicas pelos professores que efetivaram as intervenções necessárias para possibilitar a aprendizagem dos alunos. 
Ao trabalhar o desenvolvimento de noções matemáticas a partir da literatura infantil, Zacarias e Moro (2005) desenvolveram uma pesquisa que envolveu a realização de sessões de aprendizagem sobre noções da aritmética elementar apresentadas na forma de problemas sobre eventos da história infantil, com crianças préescolares. Os resultados apontaram para a realização e expressão de cálculos envolvendo diversas operações e medidas pelas crianças e discutiram a importância das histórias infantis como contexto favorável às elaborações matemáticas na educação infantil e como forma de integrar o trabalho da matemática ao de exploração do vocabulário e da imaginação infantis, a partir das formas de intervenção do professores.

Ao sinalizar algumas práticas e contribuições consideradas potencializadoras para o desenvolvimento profissional de professores de ensino fundamental, Nacarato, Mengali e Passos (2009) destacam a exploração e a produção de histórias infantis, salientando que essa prática traz resultados muito satisfatórios para aprendizagem dos alunos dos anos iniciais e também para a formação inicial e/ou continuada de professores.

Considerando o exposto verifica-se a relevância do estabelecimento de novas ações nos programas de formação inicial de professores, visando a compreensão de que a matemática foi construída socialmente e faz parte do cotidiano das pessoas, favorecendo o seu processo de ensino. Nesse sentido destacamos o trabalho de exploração e produção de histórias infantis como uma proposta que visa contribuir para a ampliação do olhar dos professores sobre o ensino dessa disciplina.

\section{O processo de produção das propostas didáticas}

Para iniciar o trabalho, os alunos realizaram um levantamento de produções literárias infantis. Nessa ação puderam explorar temas ou noções matemáticas presentes nas narrativas, bem como observar se as ilustrações permitiam a realização de algumas intervenções com foco na matemática. A proposta era analisar livros de contos 
clássicos e histórias infantis presentes no cotidiano da escola, não vinculados ao propósito específico para o ensino da matemática.

A partir da análise dos livros, os alunos foram orientados a elaborar propostas de intervenção tomando por foco algumas noções matemáticas presentes nas obras, passíveis de serem introduzidas na Educação Infantil. Tais propostas poderiam explorar a narrativa e a ilustração, considerando as possibilidades de compreensão da criança, de acordo com sua idade e o nível de escolaridade em que se encontrava.

Após esta experiência e das reflexões dela decorrentes, os alunos foram organizados em grupos com o intuito de produzir uma narrativa de história infantil aliando algumas noções matemáticas às narrativas e ilustrações, de modo intencional. Encerrada esta parte da tarefa, foi proposto que elaborassem propostas de exploração do livro com fins didáticos para o ensino e aprendizagem da matemática. Após a finalização desta etapa, que envolveu 16 horasaulas de trabalho nos dias das aulas, a conclusão se deu com a produção de narrativas individuais com o intuito de possibilitar a reflexão e a organização de um texto que demonstrasse os saberes e as compreensões dos graduandos a partir dessa experiência e as possíveis contribuições para a futura prática docente.

Considerando o trabalho das cinco turmas envolvidas nesse processo foram produzidos 42 livros infantis. Vários alunos, visando ampliar o interesse das crianças pelas histórias elaboradas, produziram também materiais alternativos como suporte para contar a história, na forma de painéis ilustrados com personagens e ambientes móveis, aventais de histórias, baús e personagens com materiais reciclados, bonecos e cenários, entre outros. Essas produções foram apresentadas e socializadas entre os estudantes das diferentes turmas.

\section{Análises e Discussões}

A construção do livro infantil no decorrer da disciplina Educação Espaço e Forma, segundo relato dos alunos, propiciou a 
oportunidade de refletir sobre a utilização do livro de histórias nas salas de Educação Infantil, para além da exploração regularmente feita com as crianças, ou seja, a contação de histórias Tais resultados corroboram com os estudos de Souza e Oliveira (2010) no que se refere ao desenvolvimento de práticas pedagógicas que integram língua materna e matemática com vistas a propiciar a aprendizagem dos alunos.

Os depoimentos dos alunos indicaram que todos passaram a valorizar o livro e as narrativas infantis como elementos importantes para o ensino não apenas da linguagem, mas também da matemática e de outras áreas do conhecimento, percebendo a possibilidade de um trabalho interdisciplinar, como é possível perceber nos dizeres de MA:

[...] eu jamais tinha pensado nessa possibilidade, agora eu olho para os livros da escola e já me pergunto: tem alguma coisa que posso explorar com relação à matemática? Fico observando as figuras, os desenhos dos livros e pensando como posso trabalhar matemática com eles, é uma outra visão do material. (Excerto da narrativa escrita da aluna MA sobre o trabalho)

Alguns estudantes ressaltaram que a atividade proposta requerer um trabalo árduo de elaborar uma narrativa infantil, produzir um livro, ilustrá-lo e pensar nas intervenções que seriam feitas com as crianças. A experiência foi uma oportunidade de escrever sobre temas de interesse das crianças e que ainda não tinham encontrado nos livros na escola. Assim afirma RA:

[...]nós criamos uma história sobre o deslocamento das formigas, porque todas as vezes que vemos formigas no parque as crianças querem segui-las e saber o que elas fazem lá dentro do formigueiro. Não tinha nenhum livro que falasse disso. (Excerto da narrativa escrita da aluna RA sobre o trabalho)

Como outro exemplo, VE comenta sobre a sua produção que também considerava experiências relatadas com as crianças: 
Nosso grupo fez a história sobre a centopéia porque as crianças gostam muito dos bichinhos de jardim. Eu acho que elas vão gostar do nosso livro.(Excerto da narrativa escrita da aluna VE sobre o trabalho).

Os estudantes declararam também que o fato de produzir uma história inédita e construir um livro, sendo necessário observar o tipo de linguagem e o vocabulário a serem utilizados, a organização das ilustrações e a oportunidade de ser autor de um material didático próprio, os motivou a pensar sobre novas produções, a pesquisar e a criar materiais e novas propostas de intervenção para o trabalho com a matemática na educação infantil. Perceberam como fundamental que os professores sejam produtores da própria prática, desmistificando a ideia de que a matemática que se ensina/ aprende na Educação Infantil se reduz à contagem, ou à sequência numérica e ao reconhecimento dos números.

Nessa perspectiva MAR assim relata:

Eu fiz esse livro até que meio rápido por causa da disciplina, mas agora que eu gostei e sei que sou capaz vou fazer outro, ainda melhor. (Excerto da narrativa escrita da aluna MAR sobre o trabalho).

Para VAL a atividade, além propiciar aprendizagens para a docência, trouxe também satisfação pessoal e abriu caminho para novas aprendizagens:

[...] eu tive a oportunidade de contar a história para uma criança. Fiquei feliz porque ela gostou muito da história. Acho que meus alunos também vão gostar, acho até que posso fazer outros, com outro tema como Geometria.

A elaboração das narrativas, contemplando as potencialidades e as dificuldades na elaboração de livros infantis para trabalhar com a matemática na Educação Infantil, contribuiu para a reflexão dos alunos sobre suas próprias aprendizagens, para a identificação das dificuldades tanto com a escrita quanto com a compreensão de diferentes noções e conceitos matemáticos que emergiram durante 
o desenvolvimento do trabalho e foram discutidos ao longo do processo formativo.

Desse modo, pensar a aprendizagem das crianças e prospectar o ensino na Educação Infantil possibilitou que os alunos da graduação - professores em formação - refletissem sobre aprendizagens relacionadas à língua materna e à matemática. Tais resultados corroboram com as compreensões de Nacarato, Mengali e Passos (2009) no sentido de que essa prática traz resultados muito satisfatórios para aprendizagem na formação inicial e/ou continuada de professores.

A dinâmica de trabalho descrita foi marcante para alguns dos participantes. Isso se atestou quando, ao encontrá-los no semestre seguinte em outras disciplinas relatavam-nos suas novas experiências de contar as histórias produzidas. Em alguns casos, os alunos já começavam a atuar em escolas, como monitores ou auxiliares de classe, ou mesmo realizando estágios docente de novas disciplinas. Tiveram a oportunidade de contar sua história e utilizar seu próprio livro em momentos de intervenção a e destacaram que experiência tinha sido muito frutífera. A aluna MAR relatou que já havia produzido outra narrativa durante as férias e que as ilustrações foram elaboradas pelos alunos do Ensino Fundamental de sua turma.

Analisar as narrativas dos estudante de graduação concernentes à articulação da literatura infantil com a matemática e sobre a criação de um livro infantil para sustentar uma abordagem didática, comunga com a perspectiva de que esse tipo de trabalho na formação inicial indica que o processo vivido nos diferentes grupos em relação aos conteúdos de ensino de matemática se desenvolvem de modo significativo, promovendo aprendizagem dos graduandos, futuros professores de Educação Infantil e anos iniciais do Ensino Fundamental, além de prospectar condições para o desenvolvimento do conhecimento e das capacidades matemáticas de seus futuros alunos. 


\section{Considerações Finais}

Os resultados deste trabalho nos permitem afirmar que a estratégia de propor a elaboração de um livro infantil para trabalhar noções matemáticas com crianças pré-escolares na formação inicial em pedagogia é uma ação relevante e que produz importantes habilidades para a docência. Esse sucesso foi evidenciado quando da apresentação das histórias pelos grupos ao final do trabalho, pelas narrativas durante o semestre sobre a realização da atividade e também pelo relato dos alunos nos momentos de reflexão.

Enfatizamos que durante todo o trabalho realizado, procurando articular matemática e literatura infantil, foi enfatizada a importância de que todas as atividades e intervenções propostas para as crianças pré-escolares devem respeitar o tempo de concentração, o interesse e o engajamento das mesmas nas aulas. Sem essa especial atenção ao desenvolvimento das crianças, o trabalho fica comprometido.

Ressaltamos que os resutados desta investigação não devem configurar-se como uma solução mágica ou como uma prescrição de atividades a serem desenvolvidas e que irão garantir a aprendizagem de todos os conceitos. Ou ainda que o desenvolvimento de todas as noções matemáticas previstas para a Educação Infantil possa ser abordada a partir desta estratégia. O que se pretende é indicar qua as histórias infantis apresentam-se como uma possibilidade a ser analisada e que pode favorecer o trabalho com as crianças a partir da ludicidade e da fantasia, tão presentes nesse nível de ensino.

De maneira especial, a elaboração da história por professores, considerando as experiências das crianças, até mesmo construindo a história e as ilustrações com a ajuda da turma com a qual o professor atua.

Essa experiência se aproxima com os resultados apresentados por Oliveira e Passos (2008) no sentido de que produzir um material para ser utilizado com os alunos favorece tanto a resignificação de conteúdos específicos, como outras possibilidades de desenvolvimento profissional. 
Enfatizamos também que o diálogo, a produção das histórias infantis, a interação entre estudantes de Pedagogia, professores em formação, numa perspectiva reflexiva desenvolvida durante a disciplina de Educação Espaço e Forma, se revelou em uma prática de formação com resultados positivos para os estudantes, para as pesquisadoras que desenvolveram esse trabalho, ampliando também a possibilidade de utilização das estratégias em outras disciplinas e possibilitando novas perspectivas de pesquisa na área.

\section{Referências}

ALMEIDA, Alessandra Rodrigues; FERNANDES, Karina Luiza Silva; MEGID, Maria Auxiliadora Bueno Andrade. Vamos ao bosque? Problematizações e tratamento da informação na Educação Infantil. Educação Matemática em Revista, p. 98-105, 2017.

AZEVEDO, Priscila Domingues De. Narrativas de práticas pedagógicas de professoras que ensinam matemática na educação infantil. Bolema: Boletim de Educação Matemática, p. 857-874, 2014.

CLEMENTS, Douglas H.; STEPHAN, Michelle. Measurement in pre-K to grade 2 mathematics. Engaging young children in mathematics: Standards for early childhood mathematics education, p. 299-317, 2004.

CUNHA, Maria Isabel da. Conta-me agora!: as narrativas como alternativas pedagógicas na pesquisa e no ensino. Revista da Faculdade de Educação, v. 23, n. 1-2, 1997.

COÊLHO, Patrícia Júlia Souza; SOUZA, Elizeu Clementino. Infâncias e educação infantil em conextos rurais da Bahia: concepções e práticas educativas. Educação \& Linguagem, v. 19, n. 2, p. 19-40.

DALCIN, Andreia. Um olhar sobre o paradidático de matemática. 2002. 162f. Dissertação (Mestrado em Educação: Educação Matemática) - Faculdade de Educação, Universidade Estadual de Campinas, Campinas, 2002.

FERNANDES; Vera Maria Jarcovis Fernandes; CURI, Edda. Algumas reflexões sobre a formação inicial de professores para ensinar matemática nos anos iniciais do ensino fundamental. REnCiMa, v. 3, n. 1, p. 44-53, jan/jul 2012 
FIORENTINI, Dario. Alguns Modos de Ver e Conceber o Ensino de Matemática no Brasil. Zetetiké. Campinas: UNICAMP, vol. 3, n.2, p. 1-36, 1995.

FREITAS, Maria Teresa M.; FIORENTINI, Dario. As possibilidades formativas e investigativas da narrativa em educação matemática. Revista Horizontes - USF, Itatiba, SP, v. 25, n. 1, p.63-71, jan-jun. 2007.

GALVÃO, C. Narrativas em Educação. Ciência \& Educação, v. 11, n. 2, 2005, p. 327-345.

GRANDO, Regina Célia; TORICELI, Luana. A colaboração em um grupo de alunas da pedagogia que ensinarão matemática. Revista Eletrônica de Educação, v. 6, n. 1, mai, 2012, p.67-90.

GUIMARÃES, Selva; CARLETO, Eliana Aparecida. Narrativas orais e literatura infantil na sala de aula: um desafio interdisciplinar. Educação \& Linguagem, v. 18, n. 2, p. 1-25, 2015.

LORENZATO, Sérgio. Educação infantil e percepção matemática. Autores Associados, 2006.

MELLO, S. A. Infância e humanização: algumas considerações na perspectiva histórico-cultural. Perspectiva, v. 25, n. 1, 57-82, jan/jun. 2007

MENEZES, Luís. Matemática, literatura \& aulas. Educação e Matemática, p. 67-71, 2011.

NACARATO, Adair Mendes; MENGALI, Brenda Leme; PASSOS, Cármen Lúcia Brancaglion. A matemática nos anos iniciais do ensino fundamentalTecendo fios do ensinar e do aprender. Autêntica, 2011.

NOVO, Martín et al. Inteligencia conectiva para la educación matemática infantil. Comunicar, 2017, vol. 25, núm. 52, p. 29-39, 2017.

OLIVEIRA, Rosa Maria Moraes Anunciato de Oliveira; PASSOS, Cármen Lúcia Brancaglion. Promovendo o desenvolvimento profissional na formação de professores: a produção de histórias infantis com conteúdo matemático. Ciência \& Educação, v.14, n.2, p.315-330, 2008.

PASSOS, Cármen Lúcia Brancaglion; OLIVEIRA, Rosa Maria Moraes Anunciato; GAMA, Renata Prenstteter. Narrativas em grupo de professores e licenciandos: resignificando a aprendizagem da matemática. Revista de Educação PUCCampinas, v. 18, n. 3, p. 327-339, 2014. 
POWELL, Arthur; BAIRRAL, Marcelo. A escrita e o pensamento Matemático. Campinas, SP: Papirus, 2006.

PROENÇA Marcelo Carlos. O ensino de frações via resolução de problemas na formação de futuras professoras de pedagogia. Bolema, Rio Claro (SP), v. 29, n. 52, p. 729-755, ago. 2015.

SOUZA, Ana Paula Gestoso; OLIVEIRA, Rosa Maria Moraes Anunciato. Aprendizagem da docência em grupo colaborativo: histórias infantis e matemática. Educação e Pesquisa,v.39, n. 4, p. 859-874, 2013.

ZACARIAS, Eloísa; FARIA MORO, Maria Lucia. A matemática das crianças pequenas e a literatura infantil. Educar em Revista, n. 25, p. 275-299, 2005. 